Review Article

\title{
Combat addiction: revisited and reaffirmed
}

\begin{abstract}
Combat Addiction (CA) is identified as an unrecognized syndrome occurring within the fourth cluster of post-traumatic stress disorder (PTSD) in DSM-5. While extensively described during the Civil War, its only specific study has been a pair of papers thirty years ago by one psychiatrist with Vietnam veterans. Drawing from oral history interviews and clinical practice, this review discusses symptom constellation and high incidence of $\mathrm{CA}$ in the current generation of Middle East War veterans. Amygdalar and dopaminergic modulation are explored as factors in the high sensation-seeking personality sub-type, and further the potential of trauma-derived Toxoplasma gondii of the brain. Potential chronicity of CA is illustrated by case studies also including aged Vietnam veterans. Within the CA sub-type, clinicians are urged to reconsider assumptions of the nature and expression of PTSD, and interventions are analyzed in respect to limitations and frank contradictions of applying some common modalities with combat addicted veterans. Alternative approaches are described. Major limitations in the few recent studies touching on the syndrome are discussed, and suggestions for enhanced study offered. Given the very extroverted and recklessly endangering core expression of combat addiction, it is emphasized as a parallel public health problem begging overdue study and intervention.
\end{abstract}

Volume 7 Issue 6 - 2017

\author{
Matthew Bowen, ${ }^{1,2,3}$ Angelica Chang ${ }^{3}$ \\ 'Private Practice of Clinical Psychology, USA \\ ${ }^{2}$ Department of Military Science, James Madison University, USA \\ ${ }^{3}$ The Combat Veterans Oral History Project, USA
}

Correspondence: Matthew Bowen, Private Practice of Clinical Psychology, Charlottesville, Virginia, USA,

Email drmbowen@cmcast.net

Received: May 06, 2017 | Published: June 19, 2017

\section{Introduction}

When Post-traumatic Stress Disorder (PTSD) was being revised for DSM-5 from its prior DSM-IV classification as an anxiety disorder into a Trauma- and Stressor-Related Disorder, numerous military leaders advocated for a change in nomenclature; specifically, from PTSD to PTSI. Classification of the syndrome as an injury rather than a disorder was viewed as both consistent with military culture and means to de-stigmatize the label on behalf of treatment compliance. Nonetheless, bearing in mind the history of the diagnosis and the larger civilian population, DSM-5 retained the classification of a disorder (APA, 2013). The revision of the diagnostic criteria otherwise enlarged the major symptom clusters from three to four, with more emphasis on behavioral symptoms. A primary change within the avoidance/ numbing cluster is the addition of persistent negative emotional states. Also added is the criterion of persistent negative alterations in cognition. Further designation of negative feelings and thoughts as the core of PTSD symptomatology continues the theoretical and clinical view of the condition since its formal inception. However, this discussion considers that within the fourth symptom cluster of alterations in arousal and reactivity, its components of aggressive, reckless or self-destructive behavior can occur as overwhelmingly positive emotion and cognition. Again bearing in mind the military veteran, this process manifests most markedly within the syndrome of combat addiction.

\section{Background}

First formally described by a psychiatrist treating Vietnam veterans, combat addiction was recognized as a specific and treatment-resistant form of PTSD manifesting most clearly in those who experienced intense, repeated combat exposure. ${ }^{1,2}$ The syndrome was viewed on a continuum of mutually reinforcing excitatory states beginning with serial combat experiences and recurring as their recall. Most typically, the recall phase was referred to by patients as a "high" or "rush," followed by "coming down" into a general malaise. A need for the presence of readied weapons and engaging in combat-reminiscent activity co-occurred with substance abuse. Given its reference to a state of combat-recalling excitation as the conditioning element, Solursh identified concurrent work as reflecting his perspective, albeit less succinctly Kolb (3) Interviewing a sample of 100 veterans of active combat experience, Solursh identified 94\% recalling battle as exciting, empowering and "a high," with the majority compelled to keep loaded guns at the ready and reenact combat scenarios in outdoor environments. The assumption that the syndrome is germane to young veterans recently removed from battle was contradicted by the sample age range being 36-59 with an average of 40.5. Moreover, a concurrent sample of World War Two and Korean War veterans with combat diagnosed PTSD reported similar although less intense elements of the syndrome. In the Vietnam veterans, chronic alcohol dependence was nearly unanimous. It was also noted that within the Vietnam sample, personal histories were not generally suggestive of a predisposition to violence prior to service.

\section{Recent developments}

In their analysis of psychological factors leading to violent behavior in PTSD, psychiatrists working with veterans proposed a typology illustrated with case presentations. ${ }^{4}$ Combat addiction violence was classified a sub-type wherein PTSD in part manifests as a behavioral pattern involving aggression by affected individuals seeking to recreate the thoughts, feelings, and actions derived from combat experience; a parallel state to the original trauma of living on edge with adrenalin flowing. The clinicians opined that the driving pathology underlying combat addiction is the need to regain a sense of integration and authenticity within the self, pursued by engaging in exciting and violent behaviors. An important feature is that the individual is typically dissonant that their particular pursuit of feeling and meaning involves such unacceptable behaviors. In a review of two noted war stories, foreign correspondent David Greenway ${ }^{4}$ extracts combat addiction from both the personal experience Vietnam novel "Matterhorn" by Karl Marlantes (2010), and the Afghanistan embedded journalist memoir "War" by Sebastian Junger (2010). Both books portray how combatants risk the most severe danger and death much less for their country and commanders than their close comrades. Indeed, it is the extreme cohesiveness of the unit that compels risk and sacrifice. Both authors illuminate how within the bond of the unit, the adrenaline produced by combat is as addicting as heroin. One consequence is that life between deployments and after discharge from service is experienced as meaningless and boring. Thus, the veterans 
of both stories often re-enlisted. As one of Marlantes characters advised a comrade en route home; "You'll pretend how sorry you are because you won't be able to explain how good it felt to do things so bad." And, as Junger learned, "one of the most traumatic things about combat is having to give it up." Killgore et al., portray what they term post-combat invincibility and its association with the degree and quantity of violent experiences in battle. In particular, veterans with greater exposure to combat involving killing and severe wounding endorsed enhanced propensity for risky behaviors such as reckless driving and other high-thrill activities once stateside.

A correlation was found for ETOH abuse. A limitation of the study is in surveying sensation-seeking behaviors just three months after deployment with no follow-up. Adler et al., ${ }^{6}$ examined the effect of transition home from combat on health-related behaviors including risk-taking. Among their findings was that after controlling for PTSD, an Anger/Alientation factor assessed at four months post-deployment predicted increased risk-taking behaviors another four months later, with reckless driving and carrying an unneeded weapon predominant Kelley et al., ${ }^{7}$ followed along parallel lines in their investigation of risk propensity in army veterans with or without psychological disturbances across the deployment cycle. They found Soldiers are more likely to engage in risky behaviors post-deployment (one month) compared to pre-deployment (30days prior). This suggested changes in attitudes about risk, risk propensity, and health risk behaviors occur after a combat deployment. Specifically, participants reported increased frequency of alcohol consumption and reckless driving. Changes were most pronounced in those positive for PTSD, with this factor not statistically controlled for as in the prior study. Using post-deployment active duty $(\mathrm{AD})$ and reserve military personnel, the relation between alcohol use, aggression and cut-off scores on the PTSD checklist (PCL) was examined in the study of Brown et al., ${ }^{8}$ Excluding alcohol abuse and associated driving in the reserve group, higher PCL scores correlated with greater occurrence of problem impulsivity and verbal and physical aggression in both groups. To establish normative data for an alternate version of the Evaluation of Risks Scale (EVAR), Killgore et al., ${ }^{9}$ sampled over two thousand combat soldiers within 3 months upon returning from a year of wartime duty in Iraq in 2006. Results showed scores significantly differentiated heavy drinkers, dangerous driving, and subjects reporting recent aggressive outbursts. Combat addiction is of course not unique to the American veteran. In his study of two Danish units deployed to Afghanistan, Braender ${ }^{10}$ began from the assumption that given the transgressive nature of combat, soldiers could be expected to suppress the need for similar experience once returned to society. Instead, the findings were that being deployed to war affects excitement motivation positively even after returning to civilian life. To a highly significant extent, soldiers were strongly motivated by excitement after their return, even when controlling for gender and age. The study concluded that whether or not one deployed to Afghanistan is not what determines increased excitement motivation; rather, it was whether or not a subject had engaged in combat. The author concluded that combat soldiers can become adrenaline junkies because their physiological threshold for excitement is so altered by the (typically serial) exposure to such extreme danger.

\section{Case illustrations}

A highly decorated Vietnam veteran spent the first year stateside hospitalized after a mortar blast before recuperating at his parent's rural home. He felt profoundly isolated without veteran comrades and life seemed purposeless. Abusing alcohol, he started driving recklessly on back roads after midnight to re-create the adrenaline charge of combat. He thrilled in driving his car fast enough over a particular steep drop so as to become airborne. He recalled the "bang" of hitting the pavement and "the rush" of seeing sparks burst in the rearview, then the life threatening struggle to regain control; trees lined the narrow road and risk of crashing completed the adrenergic experience. Age sixty-seven at the time of his interview, he proclaimed: "There's nothing like your first firefight. It's better than the first sex you ever had, and as soon as a firefight is over, you can't help but look forward to the next one." A second Vietnam veteran interviewed within an oral history project described abruptly returning to his large city following a year of severe combat in the Marine infantry. He felt entirely isolated and adrift being "back in the world." Soon abusing cocaine, he reflected that the addiction was compelled by the risk of "going on patrol to get it as much as it was actually using it." His nocturnal missions of "making contact" and risking harm recreated the sensations of wartime patrols, and acquiring his drug was reinforced by being paired with the reward of its ingestion. While these veterans in their mid-sixties had both long ceased any such behaviors, their recollections are mirrored by risk-taking in Middle East War (MEW) veterans of Iraq and Afghanistan, recently in battle and still very young. The most common pairing for war traumatized MEW veterans manifesting combat addiction is ETOH abuse and reckless driving, the latter commonly on motorcycles. Thus in the near aftermath of his final deployment at age 21, a now twenty-nine-year-old highly decorated Marine described getting intoxicated then "tearing through neighborhoods" on a motorcycle in the wee hours. After a crash, his family compelled him into treatment. Unlike the Vietnam veterans, he directly attributed a suicidal component to the drive to "chasing the rush" of combat. While predictably vehicular-related behaviors are most often reported, other means of expressing combat-like thrill seeking are abundant. Another MEW marine veteran described a process more akin to the Vietnam veteran's missions to secure cocaine. In this case, the veteran obtained a concealed carry pistol permit and routinely wandered the streets of a medium-sized city late at night "just hoping someone would mess with me." He further conveyed "I only got the permit so when I did waste someone I could stay out of jail." He would typically drink to intoxication before going on his patrols, but upon returning to his abode "smoke weed to come down." Yet another veteran-a fully armed and battle-engaged medic with an airborne unit-explained that upon returning he lived in a large city and readily became certified as an emergency medical technician because "I knew that was going to be the only scene that could come close to what I was doing in Afghanistan." His inability to separate his civilian function from combat experience soon became apparent when during a "rescue" he beat an injured man with his fist because the man had caused a car crash after trying to abduct a woman he assaulted. Discharged from his job, he began to drink heavily and patrol the city streets, acutely aware that he was seeking confrontation with "anyone Arab." Seeing a man of Middle Eastern heritage arguing in a parking lot with a Caucasian woman, he followed the couple into their building. When the man then put his hands on the woman, the veteran attacked the man, beat him, and then fled the scene. A veteran of a unit engaged in much combat in Afghanistan reported that, in the immediate aftermath of the Colorado movie theater massacre, he and a comrade he served with went to theaters throughout a 100 mile radius on a nightly basis for a month. They were both armed with heavy caliber semi-automatic handguns and staked out separate sides of the theater. He conveyed their belief the Colorado event would be imitated whereupon they would terminate the perpetrator. He affirmed they were "going stir crazy" post-deployment and eagerly seized the opportunity to emulate the search and destroy activity of combat. In regard to his behavior, he related that "I know a whole bunch of guys doing the same thing." All the more given the current epidemic of domestic mass shootings, through clinical practice and 
oral history documentary the first author finds these behavior patterns in the overwhelming majority of MEW veterans of heavy combat to the same extent as Solursh with Vietnam veterans. While Solursh did not cite the incidence of PTSD in his sample, 95\% (19/20) of MEW veterans interviewed by the first author and manifesting civilian behaviors consistent with combat addiction had already been diagnosed with PTSD. Inasmuch as this figure reflects precisely the percentage of combat addiction symptoms and behaviors reported by Solursh in his much larger sample, it suggests that his subjects-albeit a decade older and removed from battle-might well be assumed to have had the same incidence of PTSD.

\section{Further considerations}

In their analysis of Israeli war veterans, Neira et al., ${ }^{11}$ concluded high-sensation seekers took greater risks in battle, performed better in combat and reported lower levels of war-related intrusion and avoidance tendencies post-deployment than low-sensation seekers. In contrast, on formal psychometric assessment there was no distinction in level of symptom severity for war-related trauma. This suggests that perhaps for the high-sensation seekers, denial of emotional trauma was compelled by higher gratification with their war experience. Parmak et al., ${ }^{12}$ examined associations between sensation-seeking, perceived need for structure, and changes in reported well-being among Estonian troops assessed before and after a six-month deployment to Afghanistan. The results found those with a high or moderate need for structure combined with high or moderate needs for sensation-seeking reported stable adjustment, while those with a similar need for structure but low sensation- seeking endorsed decreased well-being. While the results are compromised by the postdeployment assessment taking place merely 48 hours after return, it is worth noting that the subjective sense of better adjustment reflects the Israeli sample. That combat units now include females begs their inclusion in efforts to understand combat addiction. To date this is partly limited by under-representation of females in direct combat. The Braender study attempted to discriminate by gender, yet included only four female troops and noted their role had occurred only "within the wire" versus enemy engagement. To date the first author has secured only three oral histories with female veterans. Therein, two are PTSD diagnosed, and none describe any behavior suggesting combat addiction. These veterans discussed the extreme incongruity between the hyper-masculine role of combat and stateside civilian norms for females, a psychosocial circumstance perhaps contributingalong with lack of enemy-engaged combat experience and innate neuroendocrine differences-to suppression of combat derived urges post-deployment.

\section{Neurobiological underpinnings}

When surmising the Neurophysiological factor in combat addiction, Solursh referenced Van der Kolk et al., ${ }^{13}$ and their consideration of addiction to trauma. Exploring evidence for a human equivalent of "stress-induced analgesia" in animals, van der Kolk postulated that re-exposure to trauma may produce a paradoxical sense of calm and control due to opioid release, with the cessation of traumatic stimulation followed by symptoms of opioid withdrawal. That analysis further opined the process could account for voluntary re-exposure to trauma, and further implied the psychodynamic concept of attempted mastery of the meaning of the trauma. On a biopsychosocial continuum, the present analysis abides by Solursh's affirmation of the addiction to trauma model. Moreover, operant conditioning theory must also be considered. In terms of neuroanatomy, a recent essay reformulating the function of the amygdala in PTSD dovetails well with combat addiction. ${ }^{14}$ Those authors assert that views of the amygdala as only dysfunctional in PTSD might not be accurate. Rather, they suggest that the symptoms of PTSD represent sensitized versus necessarily impaired amygdalar status. They conjecture that PTSD be considered a condition wherein the amygdala is functioning optimally in service of survival. Their discussion reviews research on the effects of Toxoplasma gondii of the brain, with an emphasis on assessing amygdala functioning and behavior. Those studies reveal that people who have been infected with $\mathrm{T}$. gondii are as much as six times more likely to have had a traffic accident than those who were not infected. They go on to elucidate that related work has shown how people who test positive for $\mathrm{T}$. gondii in serological assays exhibit personality characteristics different from non-infected individuals, including higher reactive aggression and impulsive sensation seeking. In contrast to patients with the hyperarousal subtype of PTSD exhibiting increased amygdala activity, the authors also highlight the dissociative subtype, characterized by blunted emotional and physiological responses to trauma-related stimuli. They review work theorizing the dissociative subtype involves excessive activation by the prefrontal cortex in service of inhibition of the amygdala's association to traumatic stress. Again in contrast, the hyperarousal subtype is possessed of pathology residing solely in the amygdala, albeit with an abnormally strong linkage to the hippocampus. Norbury \& Husain ${ }^{15}$ reviewed correlations between sensation-seeking (SS), dopaminergic modulation and the risk for psychopathology. Particularly via D2-type receptors, high tonic dopamine levels and hyper-reactive midbrain dopaminergic responses to signals of forthcoming reward are evident in higher sensations-seekers. The review notes a theoretical account proposing the core basis for individual differences in trait SS reflects the differential activation of approach versus withdrawal mechanisms. Consistent with the view of Diamond and Zoladz on the amygdala, these authors consider that while high trait SS is commonly associated with increased levels of dysfunctional behavior, there is preliminary evidence that, under certain circumstances, high SS may be functionally useful.

As to combat addiction, it is noted where increased tolerance of high intensity stimulation may represent a protective mechanism against post-traumatic stress disorder in high sensation-seeking individuals. Moreover, they emphasize how higher SS status has been associated in humans with a general decrease in the tendency to view the world as 'threatening,' and have been associated with greater physiological pain tolerance. The review further covers studies reporting higher SS ex-prisoners of war report fewer symptoms of post-traumatic stress disorder (PTSD) and less severe psychiatric symptoms in general than low SS individuals. Higher SS as adaptive reflects precisely the oral history of a Marine veteran of heavy combat in Afghanistan: "The PTSD you come home with is everything you had to be to survive in combat; hyper-aware of every sight and sound until you become a total paranoid, not being able to sleep for s-t, and ready to waste anyone that gives you the wrong vibe. You had to get PTSD to stay alive." For such troops, the morphing of combat-engendered PTSD into highintensity approach behavior as combat addiction is encapsulated by the statement of a highly decorated Marine rifleman of the Korean War: "Marines are always on the assault." Therefore, as Norbury and Husain assert, pursuit rather than avoidance of impulses of intense stimuli may serve a protective role in coping for combat veterans.

\section{Intervention}

In his treatise on memory and PTSD, Van der Kolk ${ }^{16}$ referenced the term "The Black Hole" of trauma as applied by Pitman et al., ${ }^{17}$ Therein memories are so deeply engraved as to absorb all associations and make present life insignificant. This predominant perspective of 
PTSD compels intervention both psychosocial and somatic; patients are approached as if their disease state is entirely one of being the passive recipient of unwanted recall of the multisensory ensemble of their trauma. Yet as outlined thus far, when combat addicted patients experience aggressive, reckless and/or self-destructive behavior as extremely positive, intervention must be reformulated. Solursh urged clinicians to apprehend their own "difficulty in accepting that a patient's aggression and violence as risk-taking, recalling and even re-enacting combat could be highly pleasurable" as relief from boredom, powerlessness and a lack of any remotely comparable meaning in life. He cautioned that history taking can be compromised by reluctance to fully note a patient's description of their combat addiction behaviors. Solursh also asserted clinicians must recognize we have nothing comparable to offer. In this light it is useful to bear in mind the premise of Diamond and Zoladz that, in theory, recovery of normative brain function in severe PTSD requires treatment restoring a functional degree of cortical prefrontal gating of amygdala hyperactivity. Solursh otherwise noted some encouraging results with propranolol and clonidine. ${ }^{2}$

Further literature on intervention with combat addiction is of course as lacking as any recognizing the syndrome. Therefore further perspective derived from the roles of both combat psychohistorian and clinician are offered herein. To an extreme extent perhaps unparalleled in the civilian realm, combat veterans identify with their own. Therefore, in attempting to clinically address the profound moral wounds often carried by combat veterans of the MEW, the first author employs the technique of sharing video clips of similar recollections of World War Two veterans. For example, two Iraq veterans tormented by the memory of on separate occasions shooting and killing 13year old boys find some relief in beholding that a 91year old veteran could finally come to terms with having reflexively shot and killed "a blur" in a German uniform when it burst from an outhouse; a casualty which was but "a boy about 13 lost in the baggy uniform and with a rifle I bet he didn't even know how to shoot." Similarly, when combat addiction has been identified in a MEW veteran, video clips of Vietnam veterans recalling their thrill of firefights are shared (no World War Two or Korean War veteran has conveyed the syndrome, likely reflecting both advanced age and the different nature of their last of the traditional front-line wars). As a means of validation through identification, this intervention has been similarly useful. Bearing in mind Solursh's truism that we civilian therapists have nothing comparable to offer, the combat addicted patient is through this method readily affirmed. In practice, the first author also introduces limited and very focused bibiliotherapy, structured so as to avoid a primarily intellectual exercise. Instead, readings are offered within the visceral-experiential context first derived from the video clips and otherwise commensurate with the patient's presentation. Drawing on Civil War sources reflecting combat addiction (Dean, 1997), exquisitely germane recollections include: "Once a heart, especially a young heart, has been fired by the peal of the cannon, roar of musketry and shouts of contending forces, it soon chafes under the monotonous quiet of home." As described by the volume's author, one continually uncovers in the day-to-day letters of Civil War soldiers a devotion to the unit and fascination with exposure to battle. One wrote that his "army experience was bigger than life itself, of overwhelming importance and power, and not to be denied." Indeed, that epoch of diaries and letter writing yielded a plethora of such personal memoirs that among 21 st century troops are now largely imparted as electronic image captures. Following the reading phase, the patient is given "homework" as writing a passage that captures their optimal combat memory. If responsive to writing, elaboration is encouraged. In this light the first author cannot emphasize strongly enough that the male combat veteran per se, and in particular the combat addicted subtype, is referencing from an entirely anti-intellectual perspective. As such, it is critical to readily establish and maintain the veteran is not being subjected to an intellectual endeavor per se, no less by a civilian lacking any combat exposure. The first author--while not formally trained--is intimately familiar with art therapy. A cogent explication of its use with combat veterans made two points in particular that the first author views as complimentary to biblio- and writing therapy:

1. Non-verbal expression facilitates the expression of memories and emotions that are difficult to put into words, and

2. Symbolic expression makes progressive exposure/expression of traumatic material more tolerable and helps overcome avoidance (Collie et al., 2006).

Again given that the process puts control with the patient, it is a potential good fit for the combat addicted. Over the last seven years the first author has heard MEW combat veterans decry group therapy. A highly decorated veteran stated: "It was just one damn pity party that made me feel even worse than I did going in." Many combat veterans have advised that the core issue with group therapy is that invariably the most vocal members are those with the least combat exposure. The genuine combat veteran finds it unendurable to partake in a process they feel is dominated by impostors motivated by compensation for an undue diagnosis of PTSD. Bearing this in mind, the first author is otherwise confident that a group comprised of select combat exposed patients would yield a positive process. Unfortunately, the impossibility of scheduling a specific group of veterans living hours apart combine with insurance restrictions to render this implausible privately. On the other hand, because the Veteran's Administration setting has the potential to create an exclusive group, the first author is conferring with a major center about creating one within its inpatient program. With their syndrome derived from such an extremely somatic experience, it follows that the combat addicted veteran would be receptive to somatic therapies. In this vein the first author-while not having employed it directly in practice-has been informed by numerous veterans with combat addiction that biofeedback was a positive intervention which, as one patient described, helped him "smooth the edges off the urges." Combat is a very immediate and active motor-sensory experience, and through biofeedback the veterans are motivated and gratified by feeling they are exerting control and then getting tangible results in real time about a physical process, just as they did with their weaponry. Surely more than talk therapy, the biofeedback process is an intuitively more obvious fit for the high SS profile. This is supported by a survey wherein seventy-one percent of post-deployed MEW troops endorsed being equally or more willing to use some form of technological treatment than solely talking to a therapist in a traditional setting. ${ }^{18}$ In being specifically engineered to recreate the sensations of battle, Exposure Therapy (ET) via the technology of Virtual Reality Immersion Therapy (VRIT) must be considered. Most notably through the Virtual Iraq/Afghanistan programs, ${ }^{18}$ the combat traumatized patient is gradually re-exposed to the specifics of their experience in a simulated environment now endorsed as an "evidencebased" treatment for PTSD. The technology has rapidly progressed to simulate the critical sensory input of vibrations and smells. Also importantly, the environment is tailored to the individual experience. Yet for the combat addicted patient, the VRIT method may arguably be inherently contraindicated or at least in need of a core modification. There are two reasons for this:

1. Theoretically, VRIT proceeds from the premise that patients are unwilling or unable to embrace their traumatic events and so typically present with avoidance, 
2. Operationally, stimulus presentation is controlled by the clinician Thus as reviewed from both a neuroanatomical and syndrome manifest standpoint, the VRIT program appears founded on and possibly more suitable for the low SS patient in need of controlled, gradual re-exposure to trauma-related stimuli.

In contrast, the combat addicted patient would enter the virtual environment already attempting on their own terms to re-immerse themselves. Not only might such subjects be averse to yielding control to the clinician, it could also be contraindicated to intensely reinforce high SS behavior which likely is already putting the veteran at risk and marginalizing them in the community. These concerns are buttressed by the findings in the recent review of Steenkamp, ${ }^{19}$ which notes the studies are often published by clinics with allegiance to ET and are selective in their sample, none of which to date would have included subjects known to be combat addicted. The review further revealed that between one-third and half of veterans receiving ET do not demonstrate clinically meaningful symptom improvement. And, even when patients do improve, symptoms often remain high. Given to our knowledge no history of pharmacologic therapy specific to a PTSD sub-group identified as combat addicted, it follows that the clinician could only rely on trial and error drawing from the research on other addictions. Still, as a starting point, the first author has repeatedly heard a strong antipathy toward psychopharmacologic intervention from the CA sub-group. This also highlights two fundamental issues:

1. The need for control embedded in the personality of the combat addicted veteran and

2. That the high SS thrives on the combat addiction component of their syndrome and is resistant to drugs intended to suppress it.

As one case related: "Most guys I know feel the same way; as soon as you get diagnosed with PTSD, the V.A. ships you a packet of enough meds to goon up a racehorse. And they keep sending them no matter whether you feel they're doing you more harm than good.' Veterans relate such long delays in securing psychiatric appointments that they become left to their own devices in titrating medications. Another combat addicted veteran confided that he started "crushing and snorting" his oxycodone HCI to achieve the euphoric state akin to the aftermath of a firefight. Of course with the high incidence of ETOH abuse in this sub-group, the success of a medication regimen is often significantly if not entirely obviated.

\section{Conclusion}

Combat addiction (CA) is a pervasive condition manifesting on the DSM-5 fourth symptom cluster of post-traumatic stress disorder It is characterized by alterations in arousal and reactivity wherein aggressive, reckless or self-destructive behavior occurs as positive emotion and cognition. The symptoms of combat addiction are most consistent with an amygdalar locus. The high sensation-seeking core personality factor, particularly when expressed via D2-type receptors, high tonic dopamine levels and hyper-reactive midbrain dopaminergic responses, may be most implicated. Both the initial (and only) clinical exploration with Vietnam veterans nearly thirty years ago and the first author's recent experience with Middle East War troops strongly indicate that, among veterans of heavy combat, CA is present in the vast majority of those exposed. The condition appears to persist for well over a decade as an overt behavior and remain as a positive association for much longer, with only very advanced age suppressing it. Given its lack of identification, intervention with combat addiction can only be approached experimentally. The clinician need first bear in mind that, unlike with other dimensions of PTSD, CA is experienced by the afflicted as a positive emotion and in its earlier phases internalized as critical for survival on account of being derived from core adaptation to combat. One must recognize the symptoms offset the range of more negative experiences, e.g., depression, passivity, boredom or even survivor's guilt, associated with being back in society. The limitations of established approaches to treating PTSD in veterans-all predicated on imposing symptom suppression-must be regarded not only attitudinally, but pharmacologically as well. CA patients are prone to resist or abuse medication, and further confound the intervention by compensating with prescribed or recreational stimulants to maintain a sensation-seeking urge. The popular evidenced-based intervention of exposure therapy (ET) is thus far quite limited both by subject selection bias and marginal outcomes. The potential contraindications of ET with combat addiction cases include clinician naivete of the patient's condition and the high potential for an iatrogenic effect. Practically speaking, patient access to ET centers is and will continue to be extremely sparse. To date no longitudinal studies exist and research with U.S. troops of the Middle East War identified as combat addicted are entirely lacking. Conjectures from the very limited and preliminary data in light of the volume of troops that saw in combat in Iraq and Afghanistan (and the brief Persian Gulf War) suggest it is highly plausible that several hundred thousand mostly quite young veterans are afflicted with combat addiction. Further in that the related behaviors virtually always include reckless driving and quite often the possession of, urge to use and discharging of firearms, also usually while co-existing with severe substance abuse (most often ETOH), the public health risk is significantly enhanced. Given the exceptional challenges to traditional intervention with $\mathrm{CA}$, the first author has had some initial success with first recognizing the syndrome in patients and then validating and encouraging its safe expression through biblio-and at least limited writing therapy. While not formally recognized, combat addiction is not a new phenomenon, for the syndrome was well documented in Civil War letters and diaries. Further research into much more distant historical sources expressing combat addiction would be of great interest. To promote awareness, assessment, intervention and research of combat addiction, the first author is developing the Combat Addiction Scale $\subset$. The syndrome is arguably now the most pervasive unrecognized phenomenon within the combat trauma spectrum, and rapid advances in its understanding are needed both on behalf of the directly afflicted and general public health.

\section{Acknowledgments}

The authors are grateful for the contribution of LTC Gary Wynn MD, psychiatrist with the Center for the Study of Traumatic Stress, F Edward Hebert School of Medicine, and Uniformed Services University of the Health Sciences, Bethesda, Maryland. Dedication to the memory of Lionel Solursh M.D., a psychiatrist with combat veterans possessed of a pioneering vision and deep dedication.

\section{Conflicts of interest}

Author declares there are no conflicts of interest.

\section{Funding}

None.

\section{References}

1. Solursh L. Combat addiction post-traumatic stress disorder re-explored. Psychiatr J Univer Ott. 1988;13(1):17-20.

2. Solursh LP. Combat addiction: Overview of implications in symptom maintenance and treatment planning. Journal of Traumatic Stress. 1989;2(4):451-462 
3. Silva JA, Derecho DV, Leong GB, et al. A Classification of Psychological Factors Leading to Violent Behavior in Posttraumatic Stress Disorder. Journal of Forensic Sciences . 2001;46(2):309-316.

4. Greenway H. The addiction to war. New York Times, USA. 2010.

5. Killgore DS, Cotting DI, Thomas JL, et al. Post-combat invincibility: Violent combat experiences are associated with increased risktaking propensity following deployment. $J$ Psychiatr Res . 2008;42(13):1112-1121.

6. Adler AB, Britt TW, Castro CA., et al. Effect of Transition Home From Combat on Risk-Taking and Health-Related Behaviors. J Trauma Stress. 2011;24(4):381-389.

7. Kelley AM, Athy JR, Cho TH, et al. Risk propensity and health risk behaviors in U.S. army soldiers with and without psychological disturbances across the deployment cycle. Journal of Psychiatric Research. 2012;46(2012):582-589.

8. Brown JM, Williams J, Bray RM, et al. Post-deployment Alcohol Use, Aggression, and Post-Traumatic Stress Disorder. Military Medicine. 2012;177(10):1184-1190.

9. Killgore DS, Castro CA, Hoge CW. Preliminary Normative Data for the Evaluation of Risks Scale-Bubble Sheet Version (EVAR-B) for Large Scale Surveys of Returning Combat Veterans. Mil Med. 2010;175(10):725-731.

10. Braender M. Adrenalin Junkies: Why Soldiers Return from War Wanting More. Armed Forces \& Society. 2015;42(1):3-25.

11. Neria Y, Solomon Z, Ginzburg K, et al. Sensation seeking, wartime performance, and long-term adjustment among Israeli war veterans. Personality and Individual Differences. 2000;29(5):921-932.
12. Parmak M, Mylle JJ, Euwema MC. Sensation Seeking and Perceived Need for Structure Moderate Soldiers' Well-Being Before and After Operational Deployment. Military Behavioral Health. 2014;2(1):75-81.

13. Kolk BV, Greenberg M, Boyd H, et al. Inescapable shock, neurotransmitters, and addiction to trauma: Toward a psychobiology of post traumatic stress. Biological Psychiatry. 1985;20(3):314-325.

14. Diamond DM, Zoladz PR. Dysfunctional or hyperfunctional? The amygdala in posttraumatic stress disorder is the bull in the evolutionary China shop. J Neurosci Res . 2015;94(6):437-444.

15. Norbury A, Husain M. Sensation-seeking: Dopaminergic modulation and risk for psychopathology. Behav Brain Res. 2015;288:79-93.

16. Van der Kolk BA. The Body Keeps the Score: Memory and the Evolving Psychobiology of Posttraumatic Stress. Harv Rev Psychiatry. 1994;1(5):253-265

17. Pitman RK, van der Kolk BA, Orr SP,et al. Naloxone-Reversible Analgesic Response to Combat-Related Stimuli in Posttraumatic Stress Disorder. Arch Gen Psychiatry. 1990;47(6):541-544.

18. Rizzo AA, Graap K, Perlman K, et al. Virtual Iraq: Initial Results from a VRET Application for Combat-Related PTSD. Stud Health Technol and Inform. 2008;132:420-425.

19. Steenkamp MM. True Evidence-Based Care for Posttraumatic Stress Disorder in Military Personnel and Veterans. JAMA Psychiatry. 2016;73(5):431-432.

20. Peterson N. In Opinion: Addicted to war-learning to deal with the highs and lows, USA. 2016. 